\title{
Desenvolvimento sustentável: os avanços na discussão sobre os temas ambientais lançados pela conferência das Nações Unidas sobre o desenvolvimento sustentável, Rio+20 e os desafios para os próximos 20 anos
}

\author{
Mayana Flávia Ferreira Pimenta* \\ Aurea Maria Brandi Nardelli**
}

\section{Resumo}

O termo Desenvolvimento Sustentável vem ganhando espaço nas últimas décadas e é cada vez mais debatido junto às autoridades mundiais. O objetivo geral deste artigo é apresentar os principais eventos intergovernamentais que deram origem à Conferência das Naçóes Unidas sobre o Desenvolvimento Sustentável realizada em 2012, também conhecida por Rio +20 , e apresentar os principais temas debatidos entre os países nesta Conferência. Em seguida, apresentam-se as contribuiçôes brasileiras na Rio+20 e como a Educação Ambiental foi abordada nesta conferência, além de discutir as perspectivas para os próximos 20 anos.

Palavras-chave: Desenvolvimento Sustentável. Rio+20. Educação Ambiental.

* Graduada em Ciência Biológicas pela Fundação Universidade de Itaúna (FUIT). Bióloga, Gestora Ambiental e especialista em Ensino de Ciências.

** Doutora em Ciência Florestal Pela Universidade Federal de Viçosa (UFV). Engenheira Florestal e Consultora do Nucleus - Sustentabilidade e Mudanças Climáticas. 


\section{Introdução}

O desenvolvimento econômico está diretamente relacionado ao acúmulo de capital e pode gerar diversos benefícios para a sociedade, favorecendo o progresso do país por meio da redução da pobreza, qualificação da mão de obra, aumento de salários, melhoria na oferta e nas condiçôes de trabalho, melhoria da dieta alimentar, maior acesso à saúde, transporte, lazer e educação, dentre outros. Porém, associados ao desenvolvimento estáo os impactos ambientais e sociais, resultantes desse processo.

Nesse contexto, a sustentabilidade é uma preocupação global e tem se tornado familiar para a maioria das pessoas, principalmente nos países desenvolvidos. É discutida no sentido de reduçáo da degradaçáo ambiental, considerada como consequência imediata do crescimento econômico. O termo tem sido usado no sentido de sobrevivência humana na Terra. Pode ser interpretado, então, como a necessidade de conservar os recursos naturais a partir de limites ao crescimento das atividades humanas, o que, consequentemente, levaria à redução da taxa de degradação ambiental. Sob esse enfoque, os principais desafios a serem enfrentados seriam os problemas relacionados ao aumento do consumo e da populaçáo. (NARDELLI, 2001, p. 3).

Diante deste cenário, é indiscutível que o termo "Desenvolvimento Sustentável” vem ganhando espaço nas últimas décadas. Ele é cada vez mais debatido junto às autoridades mundiais, que discutem alternativas para reduzir o consumismo, otimizar a utilizaçâo dos recursos naturais e minimizar os danos ao meio ambiente, a fim de promover a melhoria da qualidade de vida.

O conceito de "Desenvolvimento Sustentável" teve início na década de 1980, através da elaboração do relatório Brundland, também conhecido como "Nosso futuro comum”, na Conferência das Naçôes Unidas sobre Meio Ambiente e Desenvolvimento (CNUMAD), realizada em 1987 (WCED, 1987). Segundo este documento, o desenvolvimento sustentável é "o desenvolvimento que garante o atendimento das necessidades do presente sem comprometer a habilidade das geraçôes futuras de atender suas necessidades" (MUELLER, 1995).

Desde então, vários autores e organizaçôes mundiais têm buscado conceituar esse tema. Segundo Moretto e Giacchini (2005, p. 3), "o conceito de desenvolvimento sustentável apresenta-se de forma ampla, envolvendo a questão produtiva, a questáo social e a questão ambiental". Em outras palavras, deve abranger de forma integrada os aspectos econômicos, sociais e ambientais, que são os pilares deste modelo de desenvolvimento. 
No início da década de 1970, ambientalistas e algumas organizações mundiais iniciaram as discussōes em favor da preservação do meio ambiente. Entretanto, a ideia de que os recursos naturais eram inesgotáveis ainda predominava e as açóes para a conservação ambiental não estavam sendo efetivas. Buscando organizar o debate em nível internacional, em 1972, a Organização das Naçóes Unidas (ONU) lançou a 1a Conferência Mundial sobre o Homem e o Meio Ambiente, em Estocolmo. Porém, o grande marco ambiental aconteceu em 1992 na Conferência das Naçóes Unidas sobre o Meio Ambiente e o Desenvolvimento (CNUMAD), conhecida como ECO - 92.

Vinte anos após a sua realização, novamente o Rio de Janeiro é cenário para o mesmo debate. No entanto, a situação mostra-se claramente mais grave, pois os bens naturais do planeta e algumas fontes vitais encontram-se reduzidas ou esgotadas. Há carência de área para plantar e colher, de água potável para consumo e para pesca, além de muitos problemas para alimentação do número recorde de sete bilhóes de habitantes na Terra, alcançado em 2011. Especialmente na última década, o tema do aquecimento global e das alterações climáticas tem recebido algum destaque na sociedade, com participação maior dos cientistas e do jornalismo na divulgação destes temas. Há vários e incontáveis fatores que demonstram que a crise ambiental é global e que o homem é o maior responsável pela poluiçáo, pela devastaçáo e pelo uso inadequado dos bens naturais. (GIRARDI; MORAES; LOOSE, 2012, p. 2).

Desse modo, o presente estudo teve como objetivo geral avaliar os avanços na discussão sobre os temas ambientais e os futuros desdobramentos e desafios lançados em 2012 pela Conferência das Naçóes Unidas sobre o Desenvolvimento Sustentável, Rio+20. Como objetivo específico, buscou-se responder às seguintes questôes:

¿Qual foi a contribuição brasileira para a Conferência Rio+20?

¿ Como a Educação Ambiental foi abordada nessa Conferência?

¿Qual é a dimensão atual do tema "sustentabilidade" e quais são os desafios a serem enfrentados nos próximos 20 anos?

Para tanto, por meio de revisão de literatura, que consiste na procura de referências teóricas para análise do problema de pesquisa e, a partir das referências publicadas, fazer as contribuições científicas ao assunto em questão (LIBERALI, 2011), realizou-se um resgate histórico das diferentes fases e da evolução nas discussōes a respeito do Desenvolvimento Sustentável, até culminar na realização da Rio+20. 


\section{Rio + 20: como chegamos até aqui?}

No final da década de 1960, o desenvolvimento do país priorizava, dentre outros, investimentos nas áreas de petróleo, energia, siderurgia e infraestrutura. Paralelamente ao crescimento desses setores, começaram a surgir demandas ambientais em função dos impactos gerados por suas atividades. Soares (2003) afirmou que, antes desse período, seria inútil qualquer manifestação internacional global sobre meio ambiente, uma vez que a degradação deste começou a preocupar os estados internacionais somente na década de 1960. Para o autor, a intensificação dos impactos ambientais aconteceu justamente nos anos que antecederam a Conferência de Estocolmo.

Segundo Brüseke (1994), no início da década de 1970, o Clube de Roma, por meio das discussôes de Dennis L. Meadows e de um grupo de pesquisadores, publicou o estudo "Limites do Crescimento". As conclusóes do grupo enfatizaram o crescimento populacional e as pressóes exercidas sobre os recursos naturais em função da acelerada industrialização e urbanização. Pouco tempo depois, em junho de 1972, foi realizada na cidade de Estocolmo a Conferência das Naçôes Unidas para o Meio Ambiente, conhecida também por Conferência de Estocolmo, da qual o Brasil foi um dos participantes.

Realizada há mais de quarenta anos, a Conferência de Estocolmo foi o primeiro grande passo em busca da superação dos problemas ambientais. As propostas ali apresentadas foram baseadas no relatório do Clube de Roma. Entretanto, apresentavam soluçóes para os problemas de caráter ambiental.

Em Estocolmo foram discutidos aspectos vinculados à poluição atmosférica e foi decidida a criaçẫo do Programa das Naçôes Unidas para o Meio Ambiente (Pnuma), que passou a comandar as discussóes ambientais em escala mundial. Mas o principal debate ocorreu entre os desenvolvimentistas e os zeristas. Os primeiros eram representados pelos países pobres, que desejavam o desenvolvimento. Os segundos, baseados no relatório Limites para o crescimento (Meadows et al., 1973), que indicava uma escassez de recursos naturais para prover a base material da existência segundo o padrão capitalista de produçáo e consumo, sugeriram o crescimento zero da economia dos países pobres. A estagnação econômica não foi aceita, e os países em desenvolvimento passaram a receber investimentos, em especial por meio da instalaçáo de indústrias que degradam o ambiente, gerando a chamada divisão internacional dos riscos técnicos do trabalho. Observou-se claramente uma vitória dos países mais frágeis militarmente, o 
que não pode ser considerado um fracasso, ainda que associada a ela tenham sido criados muitos passivos ambientais em seus territórios. (RIBEIRO, 2010, p. 76).

Nessa conferência, o Brasil defendia que o crescimento econômico não deveria ser sacrificado em favor da preservação do meio ambiente, e que os países desenvolvidos deveriam pagar pelos esforços em busca dessa preservação.

Após a Conferência de Estocolmo, em 1972, a educação ambiental passou a receber atenção especial em praticamente todos os fóruns relacionados com a temática do desenvolvimento e do meio ambiente (BARBIERI; SILVA, 2011).

Na década de 1980, criou-se a Comissão Mundial sobre o Meio Ambiente e Desenvolvimento (CMMAD), pela Assembleia Geral da ONU, presidida por Gro Harlem Brundtland. Essa Comissáo, em 1987, lançou o relatório Nosso Futuro Comum, conhecido também como Relatório Brundtland. Nesse relatório, o termo desenvolvimento sustentável foi definido como "[...] o desenvolvimento que satisfaz as necessidades presentes sem comprometer a capacidade das geraçóes futuras de suprirem suas próprias necessidades" (CMMAD, 1991, p. 7). Estão implícitas no Relatório a noção de limites ao desenvolvimento e a ênfase de que os países ditos "em desenvolvimento" não poderiam seguir o mesmo ritmo de crescimento econômico dos países "desenvolvidos", pois os recursos naturais necessários estariam ameaçados. (FREITAS; NÉLSIN; NUNES, 2012, p. 44).

O Relatório Brundtland (WCED, 1987), publicado em 1987, ressaltou os riscos do uso descontrolado dos recursos naturais, sem levar em consideração a capacidade dos ecossistemas de suportar esse consumo, e, indiretamente, indicou que os países em desenvolvimento deveriam frear o seu crescimento econômico.

Nesse contexto histórico surge, então, o conceito de "Desenvolvimento Sustentável":

O discurso da sustentabilidade subdivide-se em duas vertentes: a do desenvolvimento sustentável e a da modernização ecológica. O desenvolvimento sustentável é um dos discursos ambientais mais influentes, mas, talvez, um dos mais ambíguos. Dryzek (1997) comenta que existem dúvidas sobre o que, de fato, significa o termo "desenvolvimento sustentável", sendo que inúmeras definições já foram formuladas, inclusive como forma de colocar as ideias e os interesses de outros discursos (como o do sobrevivencialismo) em nova roupagem. A essência do discurso baseia-se na compreensão de que o 
desenvolvimento econômico é necessário, principalmente para atender às necessidades dos países mais pobres, mas que estes não poderáo seguir o caminho trilhado pelos países ricos, pois o planeta Terra náo suportaria. Assim, é necessário que o desenvolvimento econômico seja guiado por princípios ambientais e sociais. (WENCESLAU, ANTEZANA, CALMON, 2012, p. 592).

Percebe-se que a noção da importância dos pilares sociais e ambientais passa a nortear as discussóes, porém, como suporte ao pilar econômico.

Em 1992, a ONU preparou no Brasil a realização da maior conferência sobre meio ambiente desde Estocolmo, a Conferência das Naçóes Unidas sobre Meio Ambiente e Desenvolvimento, ou Cúpula da Terra, conhecida também por Rio-92 ou Eco-92. Esta conferência reuniu delegaçóes de 175 países, diversos representantes de Organizações Não Governamentais (ONG's) e grande parte da população brasileira e de outras partes do mundo, consolidando o conceito de desenvolvimento sustentável.

Diferentemente de Estocolmo, nessa conferência foram aprovados cinco documentos oficiais: três convençóes (Biodiversidade, Desertificação e Mudanças Climáticas), uma Declaração de Princípios e a Agenda 21. "Os países ricos declararam a sua intenção de contribuir com $0,7 \%$ do seu PIB para ajudar os países em desenvolvimento e foi decidida a criação de um fundo especial para financiar programas ambientais nos países pobres, o Global Environmental Fund (GEF)" (JATOBÁ; CIDADE; VARGAS, 2009, p. 58).

No Brasil, a Agenda 21 foi desdobrada por meio de um processo de planejamento participativo semelhante a um plano nacional de desenvolvimento sustentável, e em diversas instâncias (governamental, empresarial e outros setores da sociedade) tornou-se um importante documento com princípios, compromissos e objetivos (MALHEIROS; PHLIPPI JUNIOR; COUTINHO, 2008).

Contando com a participação ativa da sociedade civil e de ONG's de centenas de países, um importante documento que equivale à Declaração Universal dos Direitos Humanos para a área de Meio Ambiente foi aprovado pela ONU: a "Carta da Terra", em cujo preâmbulo constam os seguintes dizeres:

Estamos diante de um momento crítico na história da Terra, numa época em que a humanidade deve escolher o seu futuro. À medida que o mundo torna-se cada vez mais interdependente e frágil, o futuro enfrenta, ao mesmo tempo, grandes perigos e grandes promessas. Para seguir adiante, devemos reconhecer que, no meio da uma magnífica diversidade de culturas e formas de vida, somos uma família humana e uma comunidade 
terrestre com um destino comum. Devemos somar forças para gerar uma sociedade sustentável global baseada no respeito pela natureza, nos direitos humanos universais, na justiça econômica e numa cultura da paz. Para chegar a este propósito, é imperativo que nós, os povos da Terra, declaremos nossa responsabilidade uns para com os outros, com a grande comunidade da vida, e com as futuras geraçóes. (CARTA..., 2000).

Passados dez anos da realização da Conferência do Rio de Janeiro, aconteceu em Johanesburgo, na África do Sul, a Cúpula Mundial sobre Desenvolvimento Sustentável (CMDS), Cúpula da Terra 2 ou, ainda, a Rio+10, cujo objetivo era avaliar o andamento dos compromissos firmados na Rio 92. Entretanto, os resultados apresentaram poucos avanços. Apesar das intenções manifestadas, a Rio+10 encontrou-se diante de um cenário diferente, no qual a redução da pobreza passou a ser o grande foco. Nesse novo contexto, a Rio+10 adquiriu, marcadamente, um caráter socioambiental.

Pode-se dizer que, a partir dessa Conferência, a questão social emerge então como elemento fundamental da sustentabilidade. Isso ressaltou a necessidade de considerar a inclusão social, nas suas diversas escalas (local, nacional e global), como fator-chave na construção da sustentabilidade, mas também expôs as contradiçóes da proposta do desenvolvimento sustentável. A constatação de que ocorreram poucos avanços nos compromissos firmados desde a Rio 92 reforçou o fato de que o desenvolvimento sustentável, enquanto propósito global estava sendo mais retórico do que real. Apesar disso, a Conferência de Johanesburgo, assim como a Rio 92, caracterizou-se mais pela apresentação de recomendaçóes do que pela definição de objetivos, metas e prazos concretos para a soluçáo dos problemas sociais e ambientais do mundo. (JATOBÁ; CIDADE; VARGAS, 2009, p. 59).

Inspirado nos movimentos internacionais, em 2004, o Instituto Brasileiro de Geografia e Estatística (IBGE) apresentou indicadores para o Desenvolvimento Sustentável, trazendo um conjunto de 50 indicadores. Segundo Malheiros, Phlippi Junior e Coutinho (2008), a maior parte deles foi obtida com base no modelo de indicadores da ONU e a partir de informaçóes existentes, problemas ou situaçóes reais, constituindo um sistema de gestão estruturado.

Embora, em sua maioria, os indicadores permitam aferir a velocidade da ação - sua dinâmica de movimento -, em muitos 
casos não respondem a perguntas básicas como: Em que nível de degradação está? Determinada taxa é aceitável ou não? Sob quais condiçóes? No curto, médio ou longo prazo? Na tentativa do desenvolvimento sustentável, os indicadores revelam-se da maior importância, pois eles devem, conjugando-se os parâmetros ambientais aos sociais e econômicos, retratar e auxiliar na busca de soluçóes e políticas para a sua possível consecução. (TAYRA; RIBEIRO, 2006. p. 86).

Entretanto, os indicadores apresentados pelo IBGE não estavam alinhados aos objetivos e metas da Agenda 21, fragilizando a estratégia construída por esta agenda de alcançar o Desenvolvimento Sustentável e a forma de subsidiar o progresso, e, consequentemente, mensurar sua avaliação (MALHEIROS; PHLIPPI JUNIOR; COUTINHO, 2008).

Dez anos depois, convocada por meio de uma resolução da Assembleia Geral da ONU, em 2009, novamente no Rio de Janeiro, aconteceu a Conferência das Naçóes Unidas sobre Desenvolvimento Sustentável, também conhecida como UNCSD, Rio 2012 ou Rio+20, cujo objetivo foi superar as dificuldades encontradas nos anos anteriores, renovar os compromissos políticos firmados rumo ao Desenvolvimento Sustentável e avaliar o progresso ambiental. Da Rio+20 resultou o relatório The Future We Want (ONU, 2012), ou seja, o "Futuro que queremos".

O Brasil, como país anfitriáo, teve um importante papel nesse contexto, focando como tema principal dessa conferência a transição para uma nova economia, a chamada "economia verde".

\section{A contribuição brasileira na Rio+20}

A Conferência das Naçóes Unidas sobre Desenvolvimento Sustentável, a Rio+20, foi realizada de 13 a 22 de junho de 2012, na cidade do Rio de Janeiro. A Rio+20 foi assim conhecida porque marcou os vinte anos de realização da Conferência das Nações Unidas sobre Meio Ambiente e Desenvolvimento (Rio-92) e contribuiu para definir a agenda do desenvolvimento sustentável para as próximas décadas.

Em função da importante realização do evento em 1992, quando se consolidou o novo conceito de desenvolvimento sustentável, o Rio de Janeiro foi o local mais apropriado para a realização da Rio+20. A Rio-92 deixou uma herança importante, principalmente a Declaração do Rio, a Agenda 21, a Convenção sobre mudanças climáticas e sobre a diversidade biológica, associados à intensa participação da sociedade civil em debates da ONU, gerando o que se chamou de "espírito do Rio". 
Como país sede e na qualidade de Presidente da Conferência, o Brasil coordenou as discussóes e trabalhou para a formação de consensos em torno da sustentabilidade. Segundo Vieira (2012), o Brasil teve um papel central nesse contexto, tanto por meio de seu governo como por meio de sua sociedade civil, baseando-se nos desafios e nos avanços na busca pelo desenvolvimento sustentável.

Investimentos em tecnologias verdes e na transiçāo para uma economia sustentável têm aumentado - mesmo durante a crise financeira internacional que eclodiu nos Estados Unidos em setembro de 2008, ainda que em ritmo mais lento - e algumas companhias começam a comunicar publicamente sua pegada ecológica e seu desempenho de indicadores de sustentabilidade, ainda que timidamente. Destacam-se ainda as ações voltadas para a chamada Economia de Baixo Carbono, conceito menos abrangente que o da Economia Verde, pois localiza as iniciativas em sustentabilidade no contexto da redução de emissōes de gases do efeito estufa e na adaptação de produtos, nos serviços e nos sistemas produtivos aos novos desafios e às oportunidades associadas à mudança do clima. Essa vertente da economia se apoia tanto em estudos científicos e socioeconômicos cada vez mais frequentes que revelam a urgência das açôes de mitigação e adaptaçáo às mudanças climáticas, quanto nas diretrizes da Convençāo-Quadro da ONU sobre Mudança do Clima, cuja principal referência até hoje é o Protocolo de Kyoto, que define meta de emissóes de carbono. (VIEIRA, 2012, p. 54).

Diversos assuntos relevantes no cenário socioambiental foram debatidos nesse momento, tais como as mudanças climáticas, as emissóes de gases de efeito estufa e os mecanismos para incentivar a Economia Verde.

O Programa Das Naçóes Unidas para o Meio Ambiente (PNUMA, 2011, p. 17) define "Economia Verde" como sendo uma economia que resulta em "melhoria do bem-estar da humanidade e igualdade social, ao mesmo tempo em que reduz significativamente riscos ambientais e escassez ecológica". Ainda segundo o PNUMA, para se alcançar a Economia Verde é necessário diminuir as emissóes de dióxido de carbono, melhorar a eficiência no consumo dos recursos e, ao mesmo tempo, ser socialmente inclusivo. Mas não se deve substituir o conceito de desenvolvimento sustentável por economia verde. Nos dias atuais já se reconhece que para se alcançar a sustentabilidade é necessário ter um modelo de crescimento econômico e mecanismos associados a esse modelo que considerem também os pilares sociais e ambientais. A sustentabilidade continua sendo o objetivo principal em longo prazo, contudo, para que seja alcançado é preciso tornar a economia mais "verde". 
Assim como a governança ambiental, o conceito economia verde já nasceu como um "conceito consenso", uma "unanimidade internacional”: Todos querem mudar as práticas presentes: governo, empresários e sociedade civil. Mas quando saímos do abstrato e passamos para uma análise geopolítica, aí começa o dissenso. (VIEIRA, 2012, p. 56).

Em concordância com Vieira (2012), este foi um problema já visível na Rio+20, onde não houve nenhuma proposição mais detalhada sobre o marco legal e institucional para políticas voltadas à economia verde, e nenhuma parte assumiu o desejo e a responsabilidade de "pagar a conta" para que este conceito se consolide.

A Rio+20 não esteve centrada, sequer foi desenhada, com o objetivo de culminar negociaçóes sobre aspectos fundamentais para o futuro ambiental do planeta, focando-se somente em discussóes, quase acadêmicas, em torno de "economia verde no contexto do desenvolvimento sustentável e a erradicação da pobreza" e sobre "o quadro institucional para o desenvolvimento sustentável". Com o mundo imerso na mais profunda crise econômica desde a Grande Depressão de 1929, foi realmente difícil convencer líderes mundiais a viajarem ao Rio em Junho para simplesmente discutir estes temas, mas sem ter que tomar decisóes, de resto, náo identificadas em momento algum para a sua ratificação e posta em prática, exceto na vaga declaraçáo política "O Futuro que Queremos". (GUIMARÃES; FONTOURA, 2012, p. 26).

Segundo dados do site oficial ${ }^{1}$ brasileiro dessa conferência, a Rio+20 abordou dois temas principais, sendo: a economia verde no contexto do desenvolvimento sustentável e da erradicação da pobreza e a estrutura institucional para o desenvolvimento sustentável. Da Rio+20 resultou o relatório The Future We Want.

O documento não contesta a estrutura da economia capitalista, porém declara na abertura que erradicar a pobreza é o maior desafio para o mundo e pré-condição para o desenvolvimento sustentável (UNITED NATIONS, 2012, parag. 2). O documento defende a visão de que a humanidade tem habilidade para atender às necessidades das geraçóes presentes sem comprometer a habilidade de as geraçóes futuras suprirem suas próprias necessidades. Esse conceito, lançado pelo Relatório Brundtland (1987), é o coração da ideia do desenvolvimento sustentável e também serviu de base filosófica da Rio 92. Esta habilidade é possível por meio da interação entre três pilares: crescimento inclusivo, desenvolvimento social e proteçáo ambiental. $\mathrm{O}$ documento foi organizado em 
volta de dois pontos principais: a economia verde e a criação do arcabouço institucional para o desenvolvimento sustentável. Grande importância é atribuída à criação de instituições e estruturas para integrar as perspectivas, promover participação e coerência, e implementar políticas científicas para o desenvolvimento sustentável nos países. (UNITED NATIONS, 2012 apud WENCESLAU; ANTEZANA; CALMON, 2012, p. 597).

O documento incentiva, ainda, a promoção da igualdade de gênero, enfatizando a liderança das mulheres e a extinção de leis discriminatórias, e destaca que "[...] não devem ser impostas regras rígidas à economia verde, e que a soberania nacional de cada país deve ser respeitada” (WENCESLAU; ANTEZANA; CALMON, 2012, p. 598).

De acordo com o Decreto 7.495, de 7 de junho de 2011, a Comissão Nacional para a Conferência das Naçôes Unidas sobre Desenvolvimento Sustentável traçou os eixos da participaçáo brasileira nessa Conferência (BRASIL, 2011). A Comissão Nacional contava com a participação do Ministério das Relaçôes Exteriores e integrada pelo Ministério da Fazenda, o Ministério do Desenvolvimento Social e Combate à Fome e o Ministério do Meio Ambiente, responsáveis, respectivamente, pelos pilares econômico, social e ambiental, seguindo os preceitos do desenvolvimento sustentável.

Nos primeiros dias da Rio+20, de 13 a 15 de junho, aconteceu a III Reuniáo do Comitê Preparatório, contando com a presença de representantes governamentais para negociaçóes dos documentos adotados na Conferência. Em seguida, entre 16 a 19 de junho, foram programados os Diálogos para o Desenvolvimento Sustentável, organizados pelo governo brasileiro com o apoio das Naçóes Unidas, e contando com a participação de alguns representantes em destaque da sociedade civil. Dentre eles o setor privado, ONG's e a comunidade científica discutiram temas relacionados ao desenvolvimento sustentável. O resultado das recomendaçôes dos Diálogos foi levado aos Chefes de Estado e de Governo presentes na Cúpula, contribuindo com a participação pública na promoção do desenvolvimento sustentável.

Por fim, de 20 a 22 de junho aconteceu o segmento de Alto Nível da Conferência, contando com a presença e também com a ausência de diversos Chefes de Estado e de Governo dos países membros das Naçóes Unidas.

Para Guimarães e Fontoura (2012), esta Conferência pode ser classificada como "Rio menos 20", uma vez que produziu poucos avanços em relação a RIO-92. Ainda para os autores, na Rio-92 surgiram as bases para um novo modelo de desenvolvimento e um novo clima de cooperaçáo internacional, cujos resultados podem ser observados a partir da adoção de convençóes, como a de Diversidade Biológica e a de Mudanças 
Climáticas. Já a Rio+20, muito foi discutido e pouco foi definido. A ausência de muitos líderes de Estado e a crise da economia mundial instalada impediram grandes avanços, deixando um documento final sem resultados concretos.

Em primeiro lugar, em nítido contraste com as Conferências de Estocolmo-72 e Rio-92, a Rio+20 năo foi concebida como uma Reunião de Cúpula, mas apenas como uma "Conferência de revisão" (UNCSD, 2012). Isto significa que a presença de Chefes de Estado e de Governo não era requisito fundamental porque não se previa a adoçáo de decisôes de Estado, o que explica o enorme esforço feito pela ONU e pela Presidente brasileira, Dilma Rousseff, para garantir a presença no Rio de Janeiro dos principais atores internacionais com capacidade de decisão. É frustrante recordar que com menos de um mês da conferência, pouco mais da metade confirmou a sua presença, com as ausências mais destacadas da Chanceler alemá, Angela Merkel, do Parlamento Europeu, e do Presidente Barack Obama, além da drástica redução da delegação enviada pela Comissão Europeia. (GUIMARÃES; FONTOURA, 2012, p. 25).

A Rio+20 iniciou uma nova caminhada para se alcançar o desenvolvimento sustentável. Houve vários desfechos para esta conferência. Segundo a ONU, um documento final de 53 páginas, acordado por 188 países, dita o caminho a ser seguido em busca da cooperação internacional em prol do desenvolvimento sustentável. Além disso, o governo, empresários e representantes da sociedade civil registraram mais de 700 compromissos com açôes concretas que alcancem resultados para necessidades específicas, como transporte e energia sustentável. Vale ressaltar que a participação da sociedade civil movimentou as discussóes junto às autoridades em favor do consumo responsável que é, atualmente, uma preocupação de todos.

\section{A Educação Ambiental na Rio + 20}

Há algumas décadas, a Educação Ambiental (EA) era resultado de açóes isoladas de alguns educadores, carecendo de políticas e diretrizes que permitissem sua implementação de forma abrangente. Santos (2000) constatou que, nas políticas públicas, a Educação Ambiental era contemplada da seguinte forma:

Em termos jurídicos propriamente ditos, vemos que no Brasil o parágrafo $1^{\circ}$, VI, do art. 255 da Constituiçáo Federal, determina ao Poder Público a promoçáo da EA em todos os níveis de ensino. Mas, apesar desta previsão constitucional, bem como o fato da EA já ser reconhecida mundialmente como 
ciência educacional e também recomendada pela UNESCO e a Agenda 21, pouco era feito no Brasil para a sua implantação concreta no ensino. O que existia era fruto dos esforços de alguns abnegados professores e educadores, não havendo a atenção que merece o tema pelo Poder Público e as entidades particulares de ensino. (SANTOS, 2000).

Sendo assim, foi necessário criar outras políticas que possibilitassem o avanço dessa prática. Em 1999, o então Presidente da República Fernando Henrique Cardoso sancionou a Lei Federal 9.795/99, que dispóe sobre a educação ambiental, institui a Política Nacional de Educação Ambiental (PNEA) e dá outras providências (BRASIL, 1999). Segundo esta lei:

[...] entendem-se por educação ambiental os processos por meio dos quais o indivíduo e a coletividade constroem valores sociais, conhecimentos, habilidades, atitudes e competências voltadas para a conservação do meio ambiente, bem de uso comum do povo, essencial à sadia qualidade de vida e sua sustentabilidade. (BRASIL, 1999).

A mesma lei, em seu artigo $10^{\circ}$, afirma que a educação ambiental deverá ser desenvolvida como parte integrante, contínua e permanente em todos os níveis e modalidades do ensino formal, e a mesma não sendo inserida como uma disciplina específica no currículo de ensino (BRASIL. 1999).

Segundo Adams (2012), o enfoque interdisciplinar presente na Lei 9.795/99 (BRASIL, 1999) é reforçado nas Diretrizes Curriculares Nacionais de Educação Ambiental:

Art. $8^{\circ}$ - A Educaçấo Ambiental, respeitando a autonomia da dinâmica escolar e acadêmica, deve ser desenvolvida como uma prática educativa integrada e interdisciplinar, contínua e permanente em todas as fases, etapas, níveis e modalidades, não devendo, como regra, ser implantada como disciplina ou componente curricular específico. (BRASIL, 2012, p. 70).

Conclui-se que, por se tratar de uma proposta interdisciplinar, as escolas e educadores devem abordar e incentivar a temática ambiental em sala de aula, para que os alunos não sejam privados deste aprendizado.

A EA proporciona discussóes que são sempre importantes para promoverem a consciência ambiental, pois é por meio dela que se formará cidadãos críticos e engajados a atuar e a cobrar resultados concretos do poder público, criando condiçóes para que as propostas e objetivos da Agenda 21 possam, efetivamente, tornar-se realidade (MALHEIROS; PHLIPPI JUNIOR; COUTINHO, 2008). 
Após a Conferência de Estocolmo de 1972, a EA passou a receber atenção especial em praticamente todos os fóruns relacionados com a temática do desenvolvimento e do meio ambiente. Dela resultou a criação do Programa das Naçóes Unidas para o Meio Ambiente (Pnuma), que viria a dividir com a Unesco as questóes relativas à EA no âmbito das Naçóes Unidas. (BARBIERI; SILVA, 2011, p. 55).

$\mathrm{Na}$ Rio+20, 260 grandes escolas e universidades de todo o mundo aprovaram uma "Declaração para Instituiçóes de Ensino Superior", comprometendo-se a incorporar questôes de sustentabilidade no ensino, pesquisa e em suas próprias gestôes e atividades da organizaçáo. Essa foi uma iniciativa importante para que o conceito de desenvolvimento sustentável esteja mais presente no dia a dia dos jovens estudantes, sobretudo dos alunos dos cursos de licenciatura. Apesar de parecer insignificante diante da quantidade de Instituiçóes de Ensino que temos hoje no mundo, já é um primeiro passo para que novas instituiçóes também aprovem esta declaração.

Outro passo importante apresentado na Rio+20 foi a criação de uma nova plataforma para coordenar a pesquisa científica para sustentabilidade global, chamada de "Terra do Futuro", que busca promover e incentivar jovens cientistas. Esta plataforma oferecerá alertas prévios sobre riscos ambientais buscando encontrar as melhores soluçóes científicas para os problemas transdisciplinares de satisfazer as necessidades humanas de alimentação, água, energia e saúde.

Também no Rio, o governo brasileiro anunciou a criação do Rio+Centre, o Centro Mundial para o Desenvolvimento Sustentável. O Rio+Centre facilitaria a pesquisa, a troca de conhecimento e o debate internacional sobre desenvolvimento sustentável, contando com a parceria do Governo do Estado do Rio de Janeiro, a Prefeitura do Rio e diversas agências da ONU, assim como instituiçóes acadêmicas, empresas e grupos da sociedade civil.

\section{Os desafios para os próximos 20 anos}

$\mathrm{Na}$ Rio+20, os países reafirmaram os princípios proferidos na Cúpula da Terra em 1992 e nas demais conferências que antecederam os debates sobre desenvolvimento sustentável, como também renovaram seus compromissos, prometendo a promoção de um futuro econômico, social e ambientalmente sustentável para o planeta e para as presentes e futuras geraçóes.

Pela primeira vez em uma conferência, a economia verde foi debatida entre os países. $\mathrm{O}$ resultado dessa discussão se encontra em uma seção do documento final da Rio+20, detalhando como as políticas econômicas podem ser uma ferramenta importante na busca pela sustentabilidade. 
No Rio, os países concordaram em fortalecer as açóes internacionais de desenvolvimento sustentável através de um fórum político de alto nível sobre desenvolvimento sustentável, a fim de integrar as dimensôes social, econômica e ambiental. Também concordaram com o fortalecimento do PNUMA.

Ficou acordado entre os países na Rio +20 a necessidade de estabelecer alguns objetivos de desenvolvimento sustentável a fim de promover açóes de desenvolvimento humano e combate a pobreza. Além disso, o Secretário Geral da ONU lançou para os países na Rio+20 o "Desafio Fome Zero", pedindo a todas as naçôes que se empenhem para que todas as pessoas desfrutem do direito a alimentação adequada o ano inteiro. Os Objetivos de Desenvolvimento Sustentável (ODS) deveráo ser estabelecidos ao longo dos próximos dois anos e a Assembleia Geral da ONU estabelecerá 30 membros para desenvolver os ODS. Os países concordaram em desenvolver uma estratégia de financiamento de recursos para que estes objetivos sejam alcançados. De acordo com o Ministério das Relaçôes Exteriores, desde 2013 as Naçôes Unidas vêm discutindo um conjunto de ODS, que deverão orientar as políticas nacionais e as atividades de cooperação internacional nos próximos quinze anos, sucedendo os Objetivos de Desenvolvimento do Milênio (ODM). Como resultado das discussôes desenvolvidas entre 2013 e 2014, o grupo de trabalho formado por 70 países, elaborou uma proposta que contém 17 Objetivos e 169 metas, envolvendo temas diversos como: erradicação da pobreza, segurança alimentar, saúde, educação, igualdade de gênero, mudança do clima, cidades sustentáveis, governança, entre outros.

Os países na Rio+20 demonstraram preocupação com a produçáo e o consumo sustentável. Foi adotado, então, um quadro de programas sobre produção e consumo sustentável estabelecido com o objetivo de guiar os países nos próximos dez anos para tornar seus padróes mais sustentáveis. O documento final da Rio+20 também incentiva o fortalecimento de pesquisas sobre as melhores tecnologias para uma produção mais limpa.

Dentre os principais legados da Rio+20, vale ressaltar os mais de 700 compromissos voluntários anunciados no Rio por grupos da sociedade civil, empresas, governos, universidades, dentre outros, para colocar em prática o desenvolvimento sustentável. Isso nos leva a concluir que a consciência socioambiental da sociedade esta evoluindo e cada vez mais impondo a sustentabilidade nas decisōes sobre o futuro do planeta.

Compromissos também foram firmados para viabilizar o acesso à energia limpa, melhorar a eficiência energética, ampliar o uso de energias renováveis e financiar a mudança para meios de transportes mais sustentáveis ao longo da próxima década. 
Por fim, os resultados da Rio+20 indicam caminhos importantes para abordar desafios que são enfrentados pela humanidade, como as mudanças climáticas, a perda da biodiversidade e a erradicação da pobreza.

\section{Considerações Finais}

A revisão bibliográfica permitiu resgatar parte da história envolvendo os eventos anteriores à conferência Rio+20 e os temas relativos ao desenvolvimento sustentável discutidos ao longo desses anos, até o encontro de 2012.

Verificou-se que a Conferência das Naçóes Unidas sobre Desenvolvimento Sustentável, a Rio+20, buscou promover a renovação do compromisso político internacional para o desenvolvimento sustentável para os próximos anos. O consenso em torno de uma maior abrangência do conceito de "sustentabilidade" e a busca por diretrizes para uma nova "economia verde" marcaram o encontro e seus desdobramentos.

Entretanto, os resultados foram considerados tímidos por grande parte dos analistas. Devido à ausência de diversos líderes de Estado e representantes de primeiro escalão e também à crise econômica mundial, não houve avanço em questôes fundamentais, como responsabilidades das naçóes e na tomada de decisóes para açôes concretas em prol da sustentabilidade. "Esta foi precisamente a grande decepção da Rio +20 , o documento final teve um conteúdo bastante minimalista na atribuição de responsabilidades futuras e seu financiamento" (WENCESLAU; ANTEZANA; CALMON, 2012, p. 603).

Como ponto positivo, é importante ressaltar que a pressão exercida pela sociedade e seu engajamento em torno das causas socioambientais é hoje um caminho sem volta. Eventos como a Rio+20 provocam a mobilização e a discussão de temas relacionados ao desenvolvimento sustentável em diversos níveis e setores da sociedade, não apenas na esfera governamental.

\section{Notas}

${ }^{1}$ Disponível em: <www.rio20.gov.br>. Acesso em: 20 set. 2012.

\section{REFERÊNCIAS}

ADAMS, Berenice Gehlen. A importância da lei 9.795/99 e das diretrizes curriculares nacionais da educação ambiental para docentes. REMOA/UFSM. V.10, n.10, p. 2148 - 2157, Out-Dez 2012. 
CARTA da Terra. The Earth Charter Initiative. San Jose, 2000. Disponível em <http://earthcharter.org/invent/images/uploads/Carta\%20da\%20Terra.pdf>. Acesso em: 16 set. 2012.

BARBIERI, José Carlos; SILVA, Dirceu da. Desenvolvimento sustentável e educação ambiental: uma trajetória comum com muitos desafios._Revista de Administração Mackenzie, São Paulo, v. 12, n. 3, jun. 2011.

BRASIL. Lei n ${ }^{\circ} 9.795$, de 27 de abril de 1999. Dispóe sobre a educaçáo ambiental, institui a Política Nacional de Educação Ambiental e dá outras providências. Diário Oficial da União, Brasília, DF, 28 abr. 1999. Disponível em: <http://www.planalto.gov.br/ccivil_03/leis/L9795.htm>. Acesso em: 3 set. 2014. BRASIL. Decreto 7.495, de 7 de junho de 2011. Cria a Comissão Nacional para a Conferência das Naçóes Unidas sobre Desenvolvimento Sustentável, o Comitê Nacional de Organização da Conferência das Naçóes Unidas sobre Desenvolvimento Sustentável, a Assessoria Extraordinária para a Conferência das Naçôes Unidas sobre Desenvolvimento Sustentável e dispóe sobre o remanejamento de cargos em comissão do Grupo-Direção e Assessoramento Superiores - DAS. Diário Oficial da União, Brasília, DF, 8 jun. 2011. Disponível em: <http://www.planalto.gov.br/ccivil_03/_Ato20112014/2011/Decreto/D7495.htm>. Acesso em: 3 set. 2014.

BRASIL. Ministério da Educação. Conselho Nacional da Educação. Resolução n ${ }^{\circ}$ 2, de 15 de junho de 2012. Estabelece as Diretrizes Curriculares Nacionais para a Educação Ambiental. Diário Oficial da União, Brrasília, DF, 18 jun. 2012. Seção 1. p. 70. BRÜSEKE, Franz Josef. A economia da sustentabilidade: princípios, o problema do desenvolvimento sustentável. In: CAVALCANTI, Clóvis (Org.). Desenvolvimento e Natureza: estudos para uma sociedade sustentável. Recife: INPSO/FUNDAJ, 1994. p.29-42

FREITAS, Rosana de Carvalho Martinelli; NÉLSIS, Camila Magalhães; NUNES, Letícia Soares. A crítica marxista ao desenvolvimento (in)sustentável. Revista Katálysis, Florianópolis, SC, v. 15, n. 1, jan./jun. 2012.

GIRARDI, Ilza Maria Tourinho; MORAES, Cláudia Herte de; LOOSE, Eloísa Beling. Bases do Jornalismo Ambiental e os desafios para a cobertura da Rio+20. Razon y Palabra, n. 79, mai./jul. 2012.

GUIMARÁES, Roberto Pereira; FONTOURA, Yuna Souza dos Reis da. Rio+20 ou Rio-20? Crônica de um Fracasso Anunciado. Ambiente \& Sociedade, São Paulo, v. 15, n. 3, p. 19 -39, set./dez. 2012. 
JATOBÁ, Sérgio Ulisses Silva; CIDADE, Lúcia Cony Faria; VARGAS, Glória Maria. Ecologismo, ambientalismo e ecologia política: diferentes visóes da sustentabilidade e do território. Sociedade e Estado, Brasília, DF, v. 24, n. 1, p. 47-87, jan./abr. 2009.

LIBERALI, Rafaela. Metodologia Científica Prática: um saber-fazer competente da saúde à educação. 2. ed. Florianópolis: Postmix Editora, 2011.

MALHEIROS, Tadeu Fabricio; PHLIPPI JUNIOR, Arlindo; COUTINHO, Sonia Maria Viggiani. Agenda 21 Nacional e Indicadores de Desenvolvimento Sustentável: contexto brasileiro. Saúde e Sociedade, São Paulo, v. 17, n. 1, p. 7-20, 2008.

MORETTO, Cleide Fátima; GIACCHINI, Jussara. Do surgimento da teoria do desenvolvimento sustentável à concepçáo de sustentabilidade: velhos e novos enfoques rumo ao desenvolvimento sustentável. In: ENCONTRO DA SOCIEDADE BRASILEIRA DE ECONOMIA AMBIENTAL, 6., 2005, Brasília. Anais... Brasília, DF: UNB, 2005.

MUELLER, Charles. As contas Nacionais e os Custos Ambientais da Atividade Econômica. Análise Econômica, Porto Alegre, v. 13, n. 23, p. 66-99, 1995.

NARDELLI, Aurea Maria Brandi. Sistemas de certificação e visão de sustentabilidade no setor florestal brasileiro. 2001. 121 p. Tese (Doutorado em Ciência Florestal) Universidade Federal de Viçosa, Viçosa, MG, 2001.

ONU. United Nations Organization. The future we want: resolution adopted by the General Assembly. Rio de Janeiro: ONU, 2012. Disponível em:

<http://www.onu.org.br/rio20/documentos/>. Acesso em: 14 mar. 2015.

PNUMA. Programa das Naçóes Unidas para o Meio Ambiente. Rumo a uma economia verde: caminhos para o desenvolvimento sustentável e a erradicação da pobreza. Genebra: UNEP, 2011.

RIBEIRO, Wagner Costa. Geografia política e gestão internacional dos recursos naturais. Estudos Avançados, São Paulo, v. 24, n. 68, mar. 2010.

SANTOS, Antônio Silveira Ribeiro dos, Educação ambiental e o poder público. Revista Jurídica, Salvador, BA, jun. 2000. Disponível em:

<http://www.aultimaarcadenoe.com.br/educacao-ambiental/>. Acesso em: 3 jul. 2014.

SOARES, Guido Fernandes Soares. Direito Internacional do Meio Ambiente: emergência, obrigaçôes e responsabilidades. São Paulo: Atlas, 2003. 
TAYRA, Flávio; RIBEIRO, Helena. Modelos de Indicadores de Sustentabilidade: síntese e avaliação crítica das principais experiências. Saúde e Sociedade, São Paulo, v. 15, n. 1, p. 84-95, jan./abr. 2006.

VIEIRA, Ricardo Stanziola. Rio+20: conferência das naçôes unidas sobre meio ambiente e desenvolvimento: contexto, principais temas e expectativas em relação ao novo "direito da sustentabilidade". Revista NEJ, Itajaí, SC, v. 17, n. 1, jan./abr. 2012.

WCED. World Commission on Environment and Development: our common future. Oslo: WCED, 1987. Disponível em: <http://www.onu.org.br/rio20/documentos/>. Acesso em: 14 mar. 2015.

WENCESLAU, Juliana; ANTEZANA, Natalia Latino; CALMON, Paulo du Pin. Políticas da Terra: Existe um novo discurso ambiental pós Rio +20 ? Cadernos EBAPE.BR, Rio de Janeiro, v. 10, n. 3, set. 2012. 
Sustainable development: Desarrollo Sostenible: los progress in the discussion of avances en la discusión acerca environmental issues de los temas ambientales launched by the United lanzadosporlaconferencia de Nations Conference on Sus- las Naciones Unidas sobre el tainable Development, Rio + desarrollo sostenible, Rio+20 20 and the challenges for the next 20 years y los retos para los próximos 20 años

\begin{abstract}
The term Sustainable Development has been gaining ground in recent decades and it is increasingly discussed with authorities worldwide. The aim of this article is to present the main intergovernmental events which helped in the creation of the United Nations Conference on Sustainable Development held in 2012, also known as Rio+20, and to present the main issues discussed among the countries in this conference. Then, the Brazilian contributions are presented in Rio+20 and how the environmental education was addressed at this conference, besides discussing the prospects for the next 20 years.
\end{abstract}

Keywords: Sustainable Development. Rio +20. Environmental Education.

\section{Resumen}

El término Desarrollo Sostenible ha ganado espacio en las últimas décadas y es cada vez más discutido junto a las autoridades mundiales. El objeto general de este artículo es presentar los principales eventos intergubernamentales que generaron a la Conferencia de las Naciones Unidas sobre el Desarrollo Sostenible realizada en el 2012, también conocida por Rio+20, y presentar los principales temas debatidos entre los paises en esta Conferencia. En seguida, se presentaron las contribuciones brasileñas en la Rio+20 y como la Educación Ambiental fue abordada en esta conferencia, además de discutir las perspectivas para los próximos 20 años.

Palabras claves: Desarrollo Sostenible. Rio+20. Educación Ambiental. 
Mayana Flávia Ferreira Pimenta

E-mail: mayanaffp@yahoo.com.br

\section{Aurea Maria Brandi Nardelli}

E-mail: aurea@smcnucleus.com.br

Enviado em: 27/2/2013

Aprovado em: 17/5/2015 